\title{
Performance-Approach Goals Deplete Working Memory and Impair Cognitive Performance
}

\author{
Marie Crouzevialle and Fabrizio Butera \\ Université de Lausanne
}

\begin{abstract}
Although longitudinal studies have consistently shown the positive impact of performance-approach goals (i.e., the desire to demonstrate one's abilities and outperform others) on academic success, they might allow some strategic behaviors such as cheating and surface studying, leaving open the question of the sheer impact of performance-approach goals on cognitive performance. We argued that the pressure to outperform others might generate outcome concerns and thus deplete working memory resources available for the activity, thereby hindering cognitive performance. Three studies carried out in a laboratory context confirmed this hypothesis. During a demanding cognitive task, performanceapproach goal manipulation hampered performance (Experiment 1) by generating distractive concerns that drew on the limited verbal component of working memory (Experiment 2). Moreover, this interference was shown to be specifically due to the activation of performance-approach goal-related thoughts during the task solving (Experiment 3). Together, the present results highlight the distractive consequence of performance-approach goals on cognitive performance, suggesting that cognitive resource allocation is divided among the storage, processing, and retrieval of task-relevant information and the activation of normative goal-attainment concerns.
\end{abstract}

Keywords: performance-approach goals, working memory, performance, modular arithmetic problems

Supplemental materials: http://dx.doi.org/10.1037/a0029632.supp

The desire to succeed at university constitutes an increasingly predominant concern for students, as illustrated by recent findings from the Higher Education Research Institute (Pryor, Hurtado, DeAngelo, Palucki Blake, \& Tran, 2010) that highlighted a constant rise of students' rating of their own drive to achieve. One may wonder whether this trend is good news and a potentially beneficial precursor of future performance of students. At first sight, the answer seems to be positive: Within the abundant amount of studies that have examined the link between students' achievement goals - the purpose of achievement activity (Elliot \& Sheldon, 1997)_and academic success, most have identified performanceapproach goals (i.e., the desire to outperform others and demonstrate one's abilities) as positive predictors of academic success (e.g., Senko, Hulleman, \& Harackiewicz, 2011). However, in

This article was published Online First August 27, 2012.

Marie Crouzevialle and Fabrizio Butera, Institut des Sciences Sociales, Université de Lausanne, Lausanne, Switzerland.

This work was supported by the Swiss National Science Foundation and was part of Marie Crouzevialle's doctoral thesis under the supervision of Fabrizio Butera. We wish to thank Sian Beilock and Andrew MattarellaMicke for kindly providing us with their modular arithmetic measures and Annique Smeding for her helpful comments on this work. We also thank the 2010 third-year social psychology seminar students at Ecole Polytechnique Fédérale de Lausanne, as well as Jean-Philippe Lachance, Anca Todirica, and Dorothy Gütermann, for their help in collecting some of the data

Correspondence concerning this article should be addressed to Fabrizio Butera, Université de Lausanne-ISS-SSP, Vidy, CH 1015, Lausanne, Switzerland. E-mail: fabrizio.butera@unil.ch reviewing the literature, it is striking to notice that this link has been assessed mainly through longitudinal designs, linking achievement goal endorsement during the academic year to final grades (e.g., Barron \& Harackiewicz, 2003; Elliot \& Murayama, 2008; Harackiewicz, Barron, Carter, Lehto, \& Elliot, 1997). It is noteworthy that the time lag between these two measures potentially paves the way to some strategic mechanisms, such as cheating and surface studying, which have been shown to be associated with performance-approach goals and have the potential to lead to good grades (Elliot, McGregor, \& Gable, 1999; Murdock \& Anderman, 2006). The present research uses an experimental setting to study for the first time the question of the sheer impact of performance-approach goals on cognitive performance.

\section{Positive and Negative Outcomes of Achievement Goals}

In academic contexts, achievement goals are acknowledged as having a notable impact on students' achievement emotions (Pekrun, Elliot, \& Maier, 2009) as well as perceptions of stakes and challenges, thereby affecting the way students work and prepare for exams (Ames, 1992; Dweck, 1986; Nicholls, 1984; for a review, Senko et al., 2011). This literature distinguishes masteryapproach goals (i.e., the desire to enhance one's abilities and competences), which have been shown to yield positive effects on intrinsic motivation, persistence after failure, challenge seeking, and deep processing of information (Ames \& Archer, 1988; Dweck \& Leggett, 1988; Grant \& Dweck, 2003; Meece, Blumenfeld, \& Hoyle, 1988), from mastery-avoidance goals (i.e., the desire to avoid stagnating in one's abilities and competences), which have frequently been associated with fear of failure (Conroy \& Elliot, 2004). A further distinction concerns performance goals, 
which also differ as a function of their orientation (Elliot, 1997, 1999; Elliot \& Church, 1997; Elliot \& Harackiewicz, 1996); indeed, performance-avoidance goals, which define the desire to avoid being outperformed by others, are generally associated with low levels of interest, high anxiety, and work disorganization (Elliot \& Church, 1997; Wolters, 2004). Conversely, outcomes associated with performance-approach goals are more controversial.

In this section, we discuss the impact of performance-approach goals on various outcomes with the exception of task performance, which constitutes the main focus of the present research and will be addressed in the next two sections. Indeed, while some studies have found positive effects on challenge construal, competence evaluation, self-efficacy, and self-esteem (for a review, see Elliot \& Moller, 2003), others have linked performance-approach goal adoption to behaviors that can be considered potentially maladaptive for achievement-related outcomes. Thus, students motivated to demonstrate competence and abilities through exam success tend to be more focused on the outcome and the way to reach a high score than on a deep and complete understanding of the course content (Jagacinski \& Nicholls, 1987; Sansone, 1986). Butler's (1992) findings provided strong evidence for this contention: She asked 12-year-old participants to complete a drawing task after the induction of either mastery or performance-approach goals. At the end of the experiment, participants were given the opportunity to access information about the task and the outcome. Results revealed that performance-approach goal participants, unlike mastery goal participants, spent more time consulting outcome information (i.e., the way to compute one's own score) than task information (different ways to execute the task).

Additionally, a great deal of empirical evidence has pinpointed that performance-approach goal endorsement leads students to perceive others as a threat (Ryan \& Pintrich, 1997), to be less inclined to share information with exchange partners (Poortvliet, Janssen, Van Yperen, \& Van de Vliert, 2007), and, in disagreement situations, to reject the other's opinion in order to impose one's own point of view (Darnon, Muller, Schrager, Pannuzzo, \& Butera, 2006). Finally, performance-approach goals have often been associated with a decline in intrinsic motivation, a preference for easy tasks, low persistence after failure, and an increase of negative affect (Dweck \& Leggett, 1988; Grant \& Dweck, 2003; Harackiewicz, Manderlink, \& Sansone, 1984; Linnenbrink, Ryan, \& Pintrich, 1999; Mangels, Butterfield, Lamb, Good, \& Dweck, 2006; Van Yperen, 2003).

\section{Performance-Approach Goals and Task Performance: Longitudinal Studies}

It is surprising that, in view of the aforementioned deleterious consequences, research has consistently shown a positive link between performance-approach goals and academic achievement (Barron \& Harackiewicz, 2003; Cury, Elliot, Da Fonseca, \& Moller, 2006; Darnon, Butera, Mugny, Quiamzade, \& Hulleman, 2009; Elliot \& Church, 1997; Elliot \& McGregor, 1999, 2001; Harackiewicz et al., 1997; Harackiewicz, Barron, Tauer, \& Elliot, 2002; Sideridis, 2005). The peculiarity of this research is that the performance-approach goals-achievement link has been assessed mainly through correlational measures: Goals are measured via self-report questionnaires - either at the beginning of the term or a few days before sitting the exams - and their relationship with actual exam performance is then examined. We argue that reliance on longitudinal methods based on self-reported goals, although granting the external validity typical of field studies, may hide two important phenomena.

First, recent research has demonstrated that students are fully aware of the social value attached to endorsement of achievement goals, in particular their potential to signal social desirability and social utility (Darnon, Dompnier, Delmas, Pulfrey, \& Butera, 2009; Dompnier, Darnon, \& Butera, 2009); relevant for the present research, students who strongly endorse performance-approach goals, although perceived as low in likability, are also perceived as highly likely to do well at university. Thus, participants' answers to achievement questionnaires can be influenced by selfpresentation concerns.

Second, a longstanding line of research has shown that performance-approach goals are often related to surface processing of course content (Elliot et al., 1999; Harackiewicz, Barron, Tauer, Carter, \& Elliot, 2000) and cheating behaviors (Anderman \& Danner, 2008; Murdock \& Anderman, 2006; Sage \& Kavussanu, 2007; Van Yperen, Hamstra, \& Van der Klauw, 2011). Such strategies may, especially in longitudinal studies, blur the interpretation of the goal-performance link. Indeed, final academic exams, which constitute the performance measure in most of the longitudinal studies, are usually announced; this may allow some students to strategically plan their preparation. Choosing one of the abovementioned strategies may prove adaptive, as it might lead to the student getting an optimal grade while avoiding strenuous work.

\section{Performance-Approach Goals and Task Performance: Experimental Studies}

In order to address these shortcomings, a few studies have been conducted in experimental settings. Senko and Harackiewicz (2005, Study 2) tested whether performance goal inductions could have a positive effect on cognitive performance, measured with a Boggle puzzle task; the results confirmed their hypothesis. However, as the authors acknowledged, the task to be solved was rather easy and, consequently, not prone to be weakened by any pressure interference. Using a similar task (Nina puzzles), Senko and Harackiewicz (2002) found no effect of performance goal induction on cognitive performance. Other researchers (Barron \& Harackiewicz, 2001; Elliot, Shell, Henry, \& Maier, 2005) went beyond this limitation through the use of more complex cognitive tasks involving mathematics calculations or verbal abilities. Elliot et al. (2005) found that both performance-approach and mastery goal inductions led to higher performance than performance-avoidance goal induction. Barron and Harackiewicz (2001) assessed performance both before and after goal manipulation, but neither of them affected the final score.

In sum, even if the above results do not allow one to draw conclusions on the relationship between performance-approach goals and cognitive performance, they provide crucial indications of the important issues to address. First, they show the importance of manipulating performance-approach goals to avoid social desirability biases in self-set goals. Second, they show the importance of reducing the lag between goal manipulation and assessment of cognitive performance, to avoid the development of 
alternative strategies to cope with the test. Third, they show the importance of choosing a task that is difficult enough to be affected by an interfering manipulation. Finally, they show the importance of the inclusion of both a baseline performance measure (prior to any goal manipulation) and a no-goal control group, which appear crucial to reveal any detrimental effect consecutive to the performance-approach goal induction. Hence, we claim that an experimental setting that would successfully address these four critical points should allow a new and crucially important clarification regarding the real cognitive consequences of performanceapproach goal endorsement.

\section{When Evaluative Pressure Creates a Dual-Task Situation}

Why, then, could it be that performance-approach goals yield a negative impact on cognitive performance? Performance-approach goals refer to normative evaluation, and to the desire to achieve above others. An interesting point for our contention is that a prominent trend of empirical research has highlighted the harmful effects of experimentally induced evaluative pressure on cognitive performance (Baumeister, 1984; Beilock \& Carr, 2001, 2005; Beilock, Kulp, Holt, \& Carr, 2004; DeCaro, Rotar, Kendra, \& Beilock, 2010; Gimmig, Huguet, Caverni, \& Cury, 2006). Beilock et al. (2004) used Gauss's modular arithmetic tasks to assess mathematical problem solving under evaluative pressure. Each participant performed both low- and high-demand problems, before and after being confronted with either a low- or highevaluative pressure manipulation; the latter was based on monetary incentives and social evaluation. Results showed that evaluative pressure impaired performance only for high-demand problems, that is, problems that relied heavily on working memory. Hence, in a high-stakes situation, participants failed even though they precisely desired to succeed. This paradoxical outcome revealed the interfering consequences of high expectations on task solving. The hypothesis, supported by the authors and called the distraction hypothesis, ascribes such performance impairment to a temporary depletion of working memory resources; indeed, pressure, by creating a dual-task environment, simultaneously asking participants to control execution of the task and to manage performance worries, divides the cognitive resources that otherwise would be devoted solely to primary task performance.

Working memory can be defined as a memory system that is used for both the temporary and active storage of a limited amount of task-relevant information and the inhibition of distractive and task nonrelevant material (Cowan, 2001; Engle, 2001; Miyake \& Shah, 1999). One of the most influential models of working memory, proposed by Baddeley and Hitch (1974) and then revised by Baddeley (1986, 2000), conceives of working memory as a multicomponent system, including an attentional component, the central executive, and two peripheral and independent systems. The central executive is responsible for many crucial activities, such as knowledge retrieval from long-term memory, selective and divided attention, updating, and task switching (Baddeley, 1996; Engle, 2002). The two peripheral systems, that is, the phonological loop and the visuospatial sketchpad, are, respectively, responsible for verbal and visuospatial information storage. The limited capacity of working memory (Norman \& Bobrow, 1975) conse- quently leads the individual to a decrease in performance if the activity to be performed solicits more cognitive resources than are available. Moreover, in dual-task situations, two different activities will have to share these limited resources in order to be simultaneously performed; if both tasks no longer have the quantity of resources they usually require, their solving will be impaired and performance will consequently decline (Navon, 1984).

Threatening contexts, such as evaluative situations, might place the individual in a situation comparable to a dual-task environment, where distractive thoughts associated with performance and the final outcome would consume cognitive resources, thereby making them no longer available for the task at hand. Studies exploring the stereotype threat phenomenon sustain this hypothesis. Hence, Schmader and Johns (2003) showed that cognitive performance of a stereotyped population (i.e., women regarding math abilities) was poorer after stereotype activation compared to conditions that did not activate the threatening stereotype and that this decrease was mediated by working memory capacity. In particular, relying on Baddeley's (1986) working memory model, Beilock, Rydell, and McConnell (2007) argued that stereotype threat manipulations might draw on the limited verbal component of working memory by generating worries that are expressed in a verbal, linguistic mode. The authors drew on the dual-task paradigm assumption to hypothesize that if both task solving and performance concerns management were consuming verbal resources, demands might exceed the amount of available verbal resources, therefore leading to an impairment of task solving. Hence, these authors varied the design of the to-be-solved arithmetic problems (Trbovich \& LeFevre, 2003) in order to manipulate the solicitation of verbal working memory during task solving and showed that a threatening condition was more harmful for performance when the task relied heavily on the verbal component than when it relied on the visuospatial component. In sum, threatening situations would deplete cognitive resources by activating outcome-related concerns that interfere with task focus by diverting part of the attention away from the task at hand (see also Muller \& Butera, 2007; Sarason, 1984; Seibert \& Ellis, 1991).

Returning to performance-approach goals, we argue that students whose goal is to secure a high score and to distance themselves from the rest of the class might similarly experience outcome-related concerns whose management will consequently consume part of their cognitive resources. This reasoning led us to claim that a performance-approach goal manipulation occurring in an experimental setting might turn out to be detrimental for cognitive performance if the task heavily solicits working memory resources.

To date, this contention has never been submitted to a stringent experimental test. It is interesting that even recently, Senko et al. (2011, p. 37) — when assessing the criticism suggesting that performance goals may undermine achievement, in particular because they may interfere with task focus-found no empirical support for this claim and concluded: "This criticism is not supported." However, none of the studies used to reach this conclusion include the four criteria listed in the previous section. Studying the effects of performance-approach goals on cognitive performance in such an experimental laboratory setting might constitute a stringent test of the distraction hypothesis, likely to fuel the above debate. 


\section{Hypothesis and Overview}

We conducted three studies to test the impact of performanceapproach goals on the availability of working memory resources during arithmetic calculation. Our general hypothesis is that the adoption of performance-approach goals might focus a part of the individual's working memory resources on performance-approach goal-related outcome concerns; consequently, the activation of the goal to be reached might shift part of the cognitive resources away from the task at hand. Thus, cognitive resource allocation would be divided among the storage, processing, and retrieval of taskrelevant information and the activation of goal-related outcome concerns; this division of attention would be deleterious if the activity to be solved solicits high demands on working memory. In order to test this hypothesis, we used a laboratory context that provided the aforementioned requirements: We manipulated performance-approach goals; assessed cognitive performance immediately following the goal manipulation; included both a baseline performance measure (prior to any goal manipulation) and a no-goal control group; and chose a task that is difficult enough to be affected by an interfering manipulation, a modular arithmetic task (Beilock et al., 2004, 2007).

Experiment 1 was designed to test whether activating performance-approach goals could indeed interfere with arithmetic problem solving. Experiment 2 tested the hypothesized process, that is, whether this interference is due to the activation of an inner language focused on goal-related concerns, drawing on the limited verbal working memory component. Finally, Experiment 3 tested whether it is specifically the activation of performance-approach goal-related content that drives the interfering effect of performance-approach goals.

\section{Experiment 1}

\section{Method}

Participants. Forty-eight undergraduate and graduate students enrolled in engineering, medicine, political and social sciences, arts and humanities, law, and business curricula in a Frenchspeaking Swiss university volunteered in the experiment. Four participants were removed from the analyses, one because of a misunderstanding of the task instructions and three because of very short response times (less than 2,500 ms) in their answers, regardless of problem difficulty, suggesting a lack of involvement in the task. The final sample consisted of 44 participants, 27 female and 17 male students, with a mean age of 21.82 years $(S D=2.27)$, who were randomly assigned to one of the two experimental conditions (24 and 20 participants in control and performanceapproach goal conditions, respectively).

Task and procedure. The task performed by participants was the same used by Beilock and colleagues (Beilock \& Carr, 2005; Beilock et al., 2004). The entire experiment was displayed on a computer screen. First, written instructions introducing the task informed participants that they would have to judge the validity of horizontally presented modular arithmetic problems such as $17 \equiv$ 5 (mod 6). To solve these problems, the participant's task was to subtract the second number from the first (i.e., here, $17-5$ ) and then to divide the obtained result by the last number. If the final result is a whole number, the statement is true; if the final result is a decimal number, the statement is false. Participants were asked to solve problems as quickly and as accurately as possible and, when they had found an answer to the item presented on the screen, to press the corresponding key ( $V$ for true and $F$ for false) on the keyboard. They were instructed to rest their right and left index fingers on these two keys, respectively, during the whole experiment

After a fixation point of $500 \mathrm{~ms}$, a modular arithmetic problem such as the one described above appeared and remained on the screen until the participant responded. The problem was then removed and feedback (i.e., the word "Correct" or "Incorrect") was provided for $1,000 \mathrm{~ms}$. The subsequent problems were individually displayed after a 1,000-ms intertrial break.

All participants performed two blocks of 24 modular arithmetic problems each. In order to vary the problems' difficulty, each block comprised eight low-demand problems requiring a singledigit no-borrow subtraction operation, such as $7 \equiv 2(\bmod 5)$; eight problems with intermediate attentional demands requiring a double-digit no-borrow subtraction operation, such as $19 \equiv 12$ $(\bmod 7)$; and eight high-demand problems requiring a double-digit borrow subtraction operation, such as $51 \equiv 19(\bmod 4)$. More precisely, high-demand problems, which imply larger numbers and borrow subtraction operations, require higher working memory resources, because participants have to both calculate and retain more intermediate results (DeStefano \& LeFevre, 2004). Half of the problems within each demand level were true, and half were false. Each problem was presented only once; presentation order within each block was randomized.

The first block of problems (Phase 1) served as a baseline measure of modular arithmetic performance for each participant. In order to avoid activating any performance- related thought during this first block, it was presented as a training block. Participants were simply asked to solve the problems as quickly and accurately as possible.

After this, participants completed a short task that aimed to activate, or not, performance-approach goals. To eliminate suspicion, it was presented as a filler task designed to rest their mind from mathematic calculations. This task involved 25 words that appeared individually either on the inferior or on the superior part of the screen and were randomly repeated twice. After a fixation point that appeared in the middle of the screen for $500 \mathrm{~ms}$, each word remained for $1,000 \mathrm{~ms}$ and was separated from the following word by a 1,000-ms blank screen. The participants' task was simply to detect the spatial location of the words and to indicate it by pressing one of two different keys. A pilot study carried out with 10 participants drawn from a separate but comparable sample had previously been conducted, in order to select words most associated with performance-approach goals. In this pilot study, participants were first provided with a definition of performanceapproach goals; then, they were asked to judge the extent to which 29 words - which were selected by the experimenter on the basis of the theoretical definition of performance-approach goals-were related to performance-approach goals, on a scale ranging from 1 (not related at all) to 7 (totally related). We finally retained the 20 words with the highest mean scores, which ranged from 4.8 to 5.8.

Hence, returning to the present experiment, participants in the experimental group had to judge the spatial location of 20 words related to performance-approach goals (e.g., superiority, success, pride), plus five filler words that were neutral regarding perfor- 
mance (e.g., screen, newspaper, language). For participants in the control condition, words were all neutral regarding performanceapproach goals. The full list of words is available from the authors.

After completion of this task, participants were to solve a second block of modular arithmetic problems. Finally, participants were debriefed and thanked.

Dependent variable. In order to examine the influence of performance-approach goal induction on problem performance, we computed a difference score by subtracting the percentage of accuracy in Phase 1 (premanipulation) from the percentage of accuracy in Phase 2 (postmanipulation). A positive difference in performance thus refers to an increase in performance from Phase 1 to Phase 2. Additionally, to make sure that the accuracy results were not the product of a speed-accuracy trade-off, we added the difference in response time (Phase 2 - Phase 1 ) as a covariate in all analyses for the three experiments.

\section{Results}

Participants solved low-, intermediate-, and high-demand modular arithmetic problems. We conducted the same analysis for each level of difficulty, as a control, although the hypothesis concerned only high-demand problems. A preliminary 2 (condition: control, performance-approach goals) $\times 2$ (gender) analysis of covariance (ANCOVA) on the accuracy difference score for high-demand problems revealed a significant main effect of gender, $F(1,39)=$ 22.80, $p<.001, P R E=.37,{ }^{1}$ showing that the difference in performance was higher for male participants than for female participants. However, as gender did not interact with the experimental manipulation $(F<1)$, this variable was not retained for further analysis. Further preliminary analyses were conducted for both accuracy and response time, with problem answers (true vs. false) entered as an additional factor. Because no interaction with this variable appeared to be significant across all three experiments, we did not include it for further analysis in any of the experiments.

A one-way ANCOVA revealed a significant difference between the control and the performance-approach goal induction groups, $F(1,41)=4.23, p<.05, P R E=.09$. As can be seen in Figure 1, means are in the expected direction, as the difference in performance was lower for the performance-approach goal group $(M=$ $-8.12, S D=20.39)$ than for the control group $(M=2.08, S D=$ 16.76). The covariate did not yield any significant effect.

Given that solving both intermediate- and low-demand problems solicits only a minor amount of resources (cf. Beilock et al., 2004), no effect of goal manipulation on difference in performance was expected. The same ANCOVA conducted on these items led to nonsignificant effects (all $F \mathrm{~s}<1$ ). ${ }^{2}$ Finally, it should be noted that the control and performance-approach groups did not differ in terms of premanipulation accuracy, $t \mathrm{~s}<1$ for low- and intermediate-demand problems; $t(42)=1.57, p=.12$ for highdemand problems.

\section{Discussion}

We designed this experiment to examine the effect of performance-approach goals on a task whose performance is prone to decrease if a part of attentional resources is consumed by the activation of task-irrelevant thoughts. Individuals had to solve

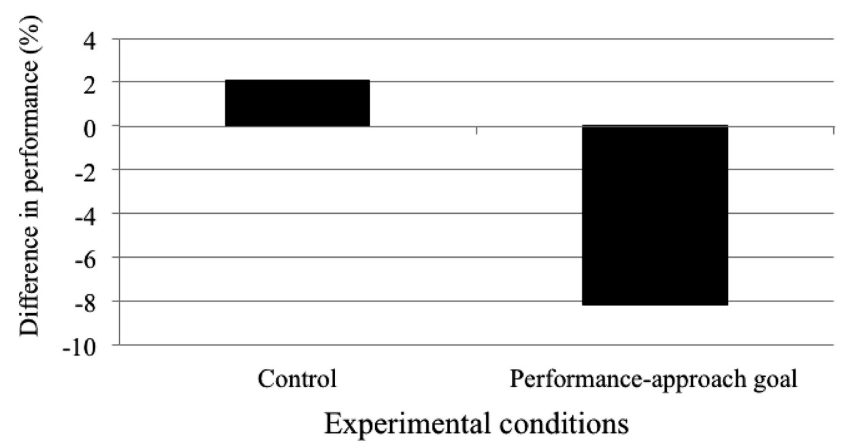

Figure 1. Experiment 1: Mean difference in performance (\%) for highdemand problems, as a function of experimental condition.

modular arithmetic problems that varied as a function of their demands in working memory. If we focus on results for highdemand problems, the implicit induction of performance-approach goals, through supraliminal presentation of words predominantly associated with performance and success, impaired the practice benefit experienced by the control group between Phase 1 and Phase 2. Thus, Experiment 1 confirms that the mere activation of performance-approach goals distracts the participants from the arithmetic calculation and therefore leads to a decrease in performance.

\section{Experiment 2}

We assumed that the impairment of performance due to performance-approach goals, actually observed in Experiment 1, could be due to a divided-attention situation, where both performance-approach goal manipulation and task solving would draw on the same resources. More specifically, performanceapproach goal induction might deplete verbal working memory resources, by activating verbal outcome concerns; this should specifically interfere with a task that heavily solicits the same limited resources. Hence, in order to test this implication, we varied the solicitation of verbal resources in the task and manipulated the design of modular arithmetic problems; we based our

\footnotetext{
${ }^{1}$ In this article, we report the PRE (proportional reduction in error; Judd \& McClelland, 1989) instead of the more common eta squared. These two effect size indices are identical in their calculation and interpretation. The issue with using eta squared is that in mathematical formalization Greek letters are used to refer to population values. Eta squared should thus be the true effect size in the population, which is by definition a value that cannot be known in experimental settings. What is commonly reported in articles are estimates of eta squared in a given sample (what Judd \& McClelland, 1989, refer to as PRE).

2 The modular arithmetic task has been widely used and validated in the research carried out by Beilock and colleagues (Beilock \& Carr, 2005; Beilock et al., 2004, 2007); it is today well established that high-demand problems solicit a larger amount of working memory resources than low-demand problems. Thus, we selected Beilock and colleagues' highdemand modular arithmetic problems as a validated measure that suited the needs of the present research. The hypothesis and the analyses focused only on high-demand problems, because this was the measure chosen for the test of our hypothesis. However, since we used the materials kindly provided by Beilock and colleagues, low-demand (and intermediate-demand, for Experiment 1) problems were included. Interested readers can consult the full accuracy data analyses in the supplemental materials available online.
} 
reasoning on Beilock et al.'s (2007) results, which demonstrated a higher implication of verbal resources when solving horizontally rather than vertically presented problems. Indeed, a vertical presentation allows the individual to mentally simulate arithmetic problem solving as if operations were set on paper (see Figure 2), which puts more demands on visuospatial resources and thereby alleviates the need to rely on verbal resources. Importantly, vertical and horizontal problems were assumed to be of equal difficulty, as they require similar executive resources in working memory and they differ only as per the solicitation of working memory peripheral systems (Beilock et al., 2007; Trbovich \& LeFevre, 2003). Beilock et al. (2007) provided experimental support for this idea, by asking participants to simultaneously solve horizontally and vertically designed problems while maintaining a phonological load in memory (i.e., a verbal secondary task). As a result, while baseline accuracy (without a secondary task) did not differ as a function of problem design, the accuracy of horizontal problems was impaired by the dual-task setting, compared to the accuracy of vertical problems. Hence, this material was retained to test our hypothesis regarding the impairment of verbal working memory after performance-approach goal manipulation. Additionally, to ensure that the findings in Experiment 1 were not method dependent, we used a different performance-approach goal manipulation, through explicit instructions. In sum, we expected a condition by design interaction, whereby a lower difference in performance should appear after performance-approach goal manipulation, compared to participants in the control group, more so when solving horizontally rather than vertically designed problems.

\section{Method}

Participants and design. One hundred and nineteen students volunteered in this experiment. The sample consisted of Frenchspeaking Swiss undergraduate and graduate students enrolled in political and social sciences, arts and humanities, law, and business curricula. Five participants were dropped from the analyses, one because of suspicion about the instructions, three because they spent an extremely short time reading the slide that contained performance-approach goal instructions (less than 5,000 ms), and one because of misunderstanding the task instructions. Thus, the final sample consisted of 114 students, 76 female and 38 male students, with a mean age of 22.02 years $(S D=3.88)$, who were randomly assigned to one of the four experimental conditions (sample sizes between 26 and 33 per condition). There were two between-participants variables, namely, instructions (performanceapproach goal, control) and problem design (horizontal, vertical).

Task and procedure. The procedure was similar to that of Experiment 1: After being introduced to modular arithmetic problem solving through written instructions, participants were asked to solve a first block of problems that was presented as a training

\begin{tabular}{|c|c|}
\hline Vertical Problems: & Horizontal Problems: \\
\hline 74 & \\
\hline$\equiv 26(\bmod 6)$ & $74 \equiv 26(\bmod 6)$ \\
\hline
\end{tabular}

Figure 2. Experiment 2: Examples of vertically and horizontally presented modular arithmetic problems. block. Then, participants in the control groups were simply informed that they were going to be performing another set of problems and that their performance would now be recorded. The participants of the experimental conditions were given extra instructions that aimed to induce performance-approach goals; to this effect, we used Darnon, Harackiewicz, Butera, Mugny, and Quiamzade's (2007) performance-approach goal instructions. Darnon et al. found in a pilot study that these instructions enhanced the adoption of performance-approach goals as measured with the Elliot and McGregor (2001) questionnaire. They thus read the following instructions, which appeared on the screen:

\begin{abstract}
During the recorded part of the task, the experimenters will assess your performance. It is important for you to be proficient, to perform well and to obtain a high score, in order to demonstrate your competence. You should know that a lot of students will do this task. You are asked to keep in mind that you should try to distinguish yourself positively, that is, to perform better than the majority of students. In other words, what we ask you here is to show your competencies, your abilities.
\end{abstract}

After this, they had to perform a second block of problems.

We also varied the design of the modular arithmetic problems between participants. Approximately half of the participants had to solve horizontally presented problems, while the other half solved vertically presented ones (see Figure 2). Each block consisted of 24 problems, dividing into 12 low-demand and 12 high-demand problems. Half of the problems within each demand level were true, and half were false. Presentation order within each block was randomized for each participant, and each problem was presented only once across the entire experiment.

After the two blocks, we asked participants to perform a lexical decision task (Koole, Smeets, van Knippenberg, \& Dijksterhuis, 1999), which was presented as an unrelated filler task designed to measure the speed of word recognition. This task was actually a manipulation check that aimed to test the efficacy of our goal induction, through the accessibility of words related to performance-approach goals in comparison with filler (neutral) words. Participants were told that letter strings would appear individually in the center of the screen and were asked to press, as quickly and as accurately as possible, the left key if it was a nonword and the right key if it was a word; 1,000 ms after the key was pressed, the next letter string appeared. In total, 64 items were randomly presented, among which 32 were nonwords and 32 were existing French words; this latter category consisted of 16 words related to performance-approach goals (e.g., success), drawn from the set used in Experiment 1, and 16 filler words (e.g., journal). Words and nonwords were matched for length. Response latencies as well as responses were recorded; errors (3.6\% of the responses, $1.7 \%$ for words) were removed from the analysis. Finally, participants were debriefed and thanked.

\section{Results}

Manipulation check: Lexical decision task. For each participant, both responses (word or nonword) and response times for each item were recorded. In order to reduce skewness in the distribution, response times longer than 1,000 ms were excluded from the analysis (Koole et al., 1999). We submitted the mean response latencies for words related or nonrelated to performanceapproach goals to a 2 (condition: control, performance-approach 
goal induction) $\times 2$ (word type: performance, neutral) mixedmodel analysis of variance (ANOVA) with repeated measures on the second factor. The analysis revealed the significant interaction between condition and word type that should be expected in case our manipulation was effective, $F(1,102)=4.28, p<.05, P R E=$ .04 ; indeed, words related to performance were identified faster than words not related to performance, more so for participants in the performance-approach goal induction group than for those in the control group. Means are reported in Table 1. Additionally, simple effects analysis revealed that words related to performance were detected faster than neutral words after performanceapproach goal manipulation, $F(1,102)=4.12, p<.05, P R E=$ .04 , while there was no significant difference in the control groups $(F<1)$. This result supports the efficacy of our induction, which appeared to activate performance-approach goals in memory.

Difference in performance. We first conducted a preliminary analysis that included gender as a factor; as neither main nor interaction effects appeared to be significant, this variable was not retained for further analysis.

A 2 (condition: control, performance-approach goal condition) $\times 2$ (design: horizontal, vertical) ANCOVA on the computed difference of performance for high-demand problems revealed a significant main effect of condition, $F(1,109)=5.30, p<.03$, $P R E=.05$, showing that the difference in performance was higher in control conditions than in performance-approach goal conditions. Moreover, the predicted interaction was significant, $F(1$, 109) $=4.36, p<.04, P R E=.04$. As can be seen in Table 2, means were in the expected direction: While our goal manipulation did not affect the solving of vertically presented problems, when solving horizontally designed problems a lower difference in performance was observed in participants confronted with the performance-approach goal manipulation, compared to participants in the control group. The covariate did not yield either main or interaction effects. Simple effects analysis revealed that the effect was significant for the horizontally designed problems, $F(1$, $109)=9.08, p<.004, P R E=0.07$, while it was not significant for vertically presented problems $(F<1)$. The ANCOVA conducted on low-demand problems led to nonsignificant effects (all $F$ s $<1$ ). Again, baseline (Phase 1) accuracy scores did not differ across experimental conditions, $F<1$, for high-demand problems, $F(3,84)=1.03, p=.38$, for low-demand problems. Also, accuracy for high-demand problems in Phase 1 did not differ as a function of problems design $(t<1)$.

Table 1

Experiment 2: Mean (SD) Response Latencies on the Lexical Decision Task as a Function of Goal Induction and Type of Words

\begin{tabular}{ccc}
\hline & \multicolumn{2}{c}{ Induction } \\
\cline { 2 - 3 } Type of words & $\begin{array}{c}\text { Performance-approach } \\
\text { goal }\end{array}$ & Control \\
\hline $\begin{array}{l}\text { Nonrelated to performance-approach } \\
\text { goals }\end{array}$ & $675(66)$ & $669(75)$ \\
$\begin{array}{l}\text { Related to performance-approach } \\
\text { goals }\end{array}$ & $661(66)$ & $674(86)$ \\
\hline
\end{tabular}

Table 2

Experiment 2: Mean (SD) Difference in Performance (\%) for High-Demand Problems as a Function of Goal Induction and Problem Design

\begin{tabular}{lrr}
\hline \multirow{2}{*}{ Induction } & \multicolumn{2}{c}{ Problem design } \\
\cline { 2 - 3 } & \multicolumn{1}{c}{ Vertical } & \multicolumn{1}{c}{ Horizontal } \\
\hline Performance-approach goal & $6.55(16.25)$ & $1.60(13.13)$ \\
Control & $6.82(15.09)$ & $14.20(15.64)$ \\
\hline
\end{tabular}

\section{Discussion}

Experiment 2 had two primary goals. First, by using another goal induction (i.e., explicit instructions), we sought to replicate the detrimental effect of performance-approach goal activation that was obtained in Experiment 1. Second, in order to unveil the process at the origin of this interference, and in particular its verbal nature, we aimed to demonstrate that the desire to succeed, by activating an inner speech associated with outcome concerns, would specifically impair the processing of a task that heavily draws on verbal working memory resources, compared to a task for which the verbal requirements have been reduced, and where both task and worries would draw on different resources.

If we focus on horizontally presented problems, which was the design used in Experiment 1, the detrimental effect of performance-approach goals on high-demand problems was replicated with a different manipulation, that is, explicit instructions emphasizing the final score and the importance of performing better than the other participants. Indeed, these instructions substantially decreased the difference in performance observed in the control group. For participants who solved problems for which the requirement of verbal resources was lower (i.e., vertically presented problems), this difference was not significant.

\section{Experiment 3}

Experiment 3 sought to replicate and extend the previous two studies by assessing to what extent the verbal interference observed in Experiment 2 was really caused by the activation of performance-approach goal content. The main innovation in the present experiment was the use of thought suppression to manipulate the accessibility of performance-approach goal-related thoughts. According to Wegner's (1994) findings, trying to get rid of a precise thought ironically tends to increase its accessibility. This ironic effect is posited to be caused by a disruption of the monitoring process (a controlled process whose function is to search for distractive thoughts), while the supervision process, which searches for the unwanted thought presence in mental content to point out suppression failure, is automatic and thus not prone to be disrupted by any additional load. This disruption should trigger the hyperaccessibility of the unwanted mental content (see Wegner, 2009; Wenzlaff \& Wegner, 2000, for a review).

On the basis of this literature, we used thought suppression instructions to enhance accessibility of either neutral or performance-approach related content. If, as we assume, performance-approach goals' harmful effect on performance is really due to their interfering content, a condition that merely manipulates performance-approach goals, as well as a condition 
that experimentally generates their hyperaccessibility (through thought suppression instructions), should be more detrimental to performance than a control condition and a condition that additionally generates accessibility of a performance-neutral topic. In other words, the thought suppression manipulation was designed to reveal that the activation of performance-approach goal-related content is actively responsible for the distractive effect reported in both Experiments 1 and 2.

\section{Method}

Participants. Participants were 98 students attending a French-speaking Swiss university, enrolled in political and social sciences, law, arts and humanities, and business curricula. Four participants were dropped from the analyses because they spent an extremely short time reading the slide that contained performanceapproach goal instructions (less than 5,000 ms). Another participant was removed from the analyses because he had not fully understood the instructions. Finally, five other participants were removed because of their short mean response time (less than 2,500 $\mathrm{ms}$ ) whatever the problem difficulty, which was associated with a high rate of errors and suggested a lack of involvement in the task. The final sample consisted of 88 students, 83 female and 5 male students, with a mean age of 24.08 years $(S D=4.88)$; six participants did not report their age. All participants were randomly assigned to one of the four experimental conditions (sample sizes between 20 and 24 per condition).

Procedure. Participants solved two blocks of 24 modular arithmetic problems that were all horizontally presented. Participants in the control group were informed simply that they were to perform another set of problems and that their performance would now be recorded. Individuals in the three other conditions were given extra instructions, which aimed to induce performanceapproach goals and were similar to those given in Experiment 2. After these instructions, participants in the performance-approach goal-only condition solved the second set of problems. For the two remaining conditions, extra instructions were given. In the performance-approach goal plus goal hyperaccessibility condition, participants were given the following instructions:

\begin{abstract}
To sum up, your score will be judged by experimenters, and you will get access to it at the end of the experiment. Try to succeed the best you can, and to obtain a high final score. Because you will be given your rank compared to the other participants, try also to outperform others.

It is now time to start and focus on the task. Now that you have read the above information, try to leave it aside. From now and for the duration of the exercise, try not to think that you must obtain a high score. You shall also try to eliminate all thoughts that are associated with your rank compared to the other participants. For example, try not to think about your wish of being better than others. ${ }^{3}$
\end{abstract}

Identical suppression instructions were given to the fourth group, except that the thoughts to be suppressed were focused on a neutral topic:

In this experiment, we also try to have regard for characteristics of the material we use, in order to ensure that it does not impact problems' readability. The sizes of problems, as well as the brightness of the screen, have been controlled, in order to ensure readability. These precautions aimed to set a favorable environment for task solving.
It is now time to start and focus on the task. Now that you have read the above last information, try to leave it aside. From now and for the duration of the exercise, try not to think about graphic characteristics of problems. You shall also try to eliminate all thoughts that are associated with the cast and location of stimuli. For example, try not to focus your attention on the brightness of the screen.

This last condition was established to focus thought suppression on a neutral and performance-irrelevant matter. We chose to focus the neutral thought suppression instructions on screen brightness and graphic characteristics of stimuli in order to obtain instructions that were neutral regarding performance but at the same time directly connected to the experiment participants were performing, like the performance-approach goal suppression instructions. Then, all participants solved the second block of problems. Finally, they were debriefed and thanked.

\section{Results}

We again assessed the interference due to the manipulations by subtracting Phase 2 accuracy from Phase 1 accuracy (in percentages). Then, in order to test our model, we used a linear regression analysis. To predict the difference in performance due to the experimental manipulation, we tested three orthogonal contrasts. The first represents the planned comparison that tests the model; the remaining contrasts are a set of orthogonal contrasts testing the residual variance. The first contrast testing the planned comparison was "1 $-1 \quad 1-1$, , respectively, associated with control, performance-approach goal-only, performance-approach goal with neutral topic hyperaccessibility, and performance-approach goal with performance-goal hyperaccessibility conditions. The second

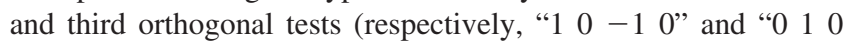
-1 ") assessed the residual variance. According to Judd and McClelland (1989), if the first contrast fits the data, it should yield a significant effect and the orthogonal contrasts should not be significant. Additionally, we entered the centered mean difference of response time (Phase 2 - Phase 1) for high-demand problems as a control, as well as the interactions between this term and the three contrasts (Yzerbyt, Muller, \& Judd, 2004). This linear regression analysis revealed that the first contrast (i.e., the model) was significant, $B=4.33, t(80)=2.10, p<.04, P R E=.05$. Conversely, the two other orthogonal contrasts were not significant, respectively, $B=0.50, t<1$, and $B=-3.30, t(80)=-1.17$, $p=.25$. As can be seen in Figure 3, means were in the expected direction: In both performance-approach goal-only $(M=-3.26$, $S D=21.06)$ and performance-approach goal plus goal hyperaccessibility $(M=3.12, S D=14.39)$ conditions, participants experienced a lower difference in performance compared to participants in both performance-approach goal plus neutral topic accessibility $(M=8.12, S D=20.79)$ and control $(M=8.93$, $S D=20.97)$ conditions. The covariate did not yield either main or interaction effects. The same analysis conducted on low-demand

\footnotetext{
${ }^{3}$ One could argue that these instructions appear contradictory and confusing for participants: At first, they read performance-approach goal instructions, and right after, they are asked to leave aside the thoughts related to this goal during task solving. However, these last instructions, far from being incongruous, are rather appropriate because they did not ask participants to ignore the previously assigned goal, but rather to leave it aside, the rationale being that "It is now time to start and focus on the task."
} 


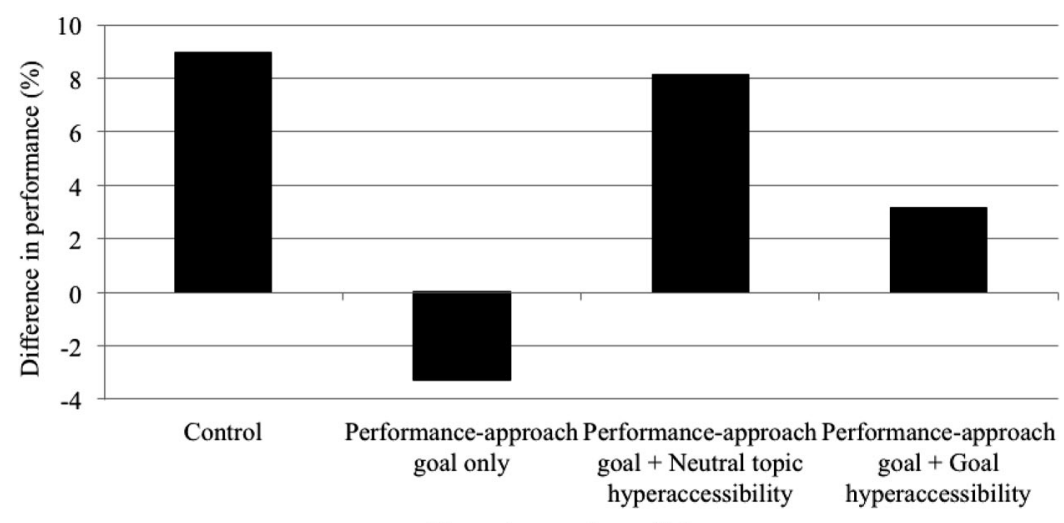

Experimental conditions

Figure 3. Experiment 3: Mean difference in performance (\%) for high-demand problems, as a function of experimental condition.

problems led to nonsignificant effects. As in the two previous studies, baseline accuracy for low- and high-demand problems did not differ as a function of condition $(F \mathrm{~s}<1)$.

\section{Discussion}

The two previous experiments revealed a detrimental effect of performance-approach goal induction; however, even though the lexical decision task included in Experiment 2 brought a first proof of performance-related thought activation throughout the experiment, Experiments 1 and 2 gave no direct evidence that the observed impairment of performance was really due to performance-approach goals' accessibility. Experiment 3 was designed to assess to what extent the activation of goal-related thoughts during the task was indeed responsible for the performance decrease. As expected, the difference in performance between pre- and postmanipulation blocks was higher for both the control group and the condition that asked participants to suppress neutral information in addition to performance-approach goal induction, compared with both the condition that merely manipulated performance-approach goals and the condition that additionally asked participants to try to suppress these goals' content during the task. Hence, results confirmed our hypothesis, suggesting that the hyperaccessibility of performance-approach goalrelated concerns - which we hypothesized to be triggered by the mere performance-approach goal manipulation and which we explicitly manipulated in Condition 4 through thought-suppression instructions-played a major role in the decrease in performance that we observed in these two conditions.

Thus, the use of performance-related thought suppression instructions, which were based on Wegner's (2009) rebound effect, appears to be particularly advantageous as it helps to clarify the mechanisms responsible for performance decrement under performance-approach goal instructions. This result adds crucial information to our reasoning, as it suggests that the verbal interference detected in Experiment 2 is caused by intrusive thoughts related to performance accessibility and outcome concerns. Such performance-related thoughts focus part of the limited working memory resources away from the task at hand, thereby decreasing performance on high-demand items.

\section{General Discussion}

The present research was conducted to assess whether an assigned performance-approach goal can interfere with mathematical problem solving and impair cognitive performance. Even though performance-approach goals have frequently been associated with some negative outcomes, such as lower information giving to partners (Poortvliet et al., 2007), a decline in intrinsic motivation (Van Yperen, 2003), and the perception of others as a threat (Ryan \& Pintrich, 1997), longitudinal studies have often reported performance-approach goals to be positive predictors of academic achievement. However, strategic behaviors such as selfpresentation concerns (Darnon, Dompnier, et al., 2009), cheating (Van Yperen et al., 2011), or surface processing (Harackiewicz et al., 2000), which have been identified as associates of performance-approach goals, might cast some doubts on the causes of the observed relationship; hence, we considered it critical to test this question in a laboratory setting designed to directly compensate for these limitations. We relied on the literature that had studied the distracting impact of evaluative pressure (Beilock et al., 2004) and threatening contexts (Beilock et al., 2007; Schmader \& Johns, 2003) to provide indirect support for our hypothesis that the endorsement of norm-driven performance-approach goals could compel individuals to divide their cognitive resources between outcome concerns and task processing, this dividedattention situation being detrimental to task processing.

Findings from the three studies reported above confirmed our hypothesis and consistently demonstrated the detrimental impact of performance-approach goal induction on mathematical problem solving. Notably, this effect was replicated with two different categories of induction, as the decrease in performance was observed both after supraliminal word presentation designed to prime performance-approach goals (Experiment 1) and after explicit instructions (Darnon et al., 2007) known to motivate participants to endorse performance-approach goals (Experiments 2 and 3). Moreover, results obtained on the lexical decision task (Experiment 2), which was designed to test performance-approach goals' accessibility in memory, corroborates the efficacy of the latter manipulation. 
As far as process is concerned, this performance-approach goal interference was found to deplete verbal resources of working memory (Experiment 2); indeed, the deleterious effect consecutive to performance-approach goal manipulation was no longer obtained when problems were vertically presented, that is, when the verbal demands of problems solving were reduced. This finding is consistent with previous results obtained with stereotype threat (Beilock et al., 2007) and performance pressure (DeCaro et al., 2010) manipulations, therefore corroborating the hypothesis that our goal manipulation consumes phonological resources, which appears to be particularly problematic if the activity one simultaneously performs also relies on the verbal component of working memory. Results observed in Experiment 3 add precious information by demonstrating, through the use of thought suppression instructions (Wegner, 1994), that this internal language consecutive to our goal manipulation essentially deals with concerns associated with the content of performance-approach goals. Hence, besides confirming the hyperaccessibility of goal-related content during the task solving, Experiment 3 also points out its interfering impact on performance.

The reported detrimental consequence of performance-approach goals on cognitive performance might appear disconcerting, especially in light of previous evidence from many longitudinal studies (see Senko et al., 2011, for a review; see also Darnon, Butera, et al., 2009) of a positive relation between students' endorsement of performance-approach goals and grades on final exams. However, we argue that such divergent results, far from being contradictory, stem precisely from methodological differences. More specifically, we chose to conduct this research in a laboratory setting to control for variables that we suspected would interfere in longitudinal studies and that were not prone to intrude into a short-term experimental study.

First, on the basis of previous work pointing out how selfpresentation concerns can motivate students to fake their answers to achievement goal questionnaires (Darnon, Dompnier, et al., 2009), we opted for an experimental induction of performanceapproach goals. Second, the modular arithmetic task is "advantageous as a laboratory task" (Beilock et al., 2004, p. 586), as it is unknown to the participants before they are introduced to it at the beginning of the experiment. The importance of this characteristic is worth mentioning for two reasons. On the one hand, it minimizes the influence of a priori knowledge on performance, and on the other hand, it enables us to obtain a precise measure of learning, via the practice benefit assessed through the evolution between the first and the second block. Results revealed that, as predicted, endorsing a performance-approach goal, as opposed to no goal (i.e., the control condition), did substantially impede the performance improvement consecutive to training.

Third, from a methodological perspective, modular arithmetic problems are known to be difficult enough to be sensitive to a distractive manipulation. This point was of importance, as former experimental research that examined the link between manipulated goals and performance used moderately complex tasks (Senko \& Harackiewicz, 2002, 2005) whose solving failed to be impacted by any induction. Our results confirmed that as far as high-demand problems were concerned, their processing was hindered by the performance-approach goal manipulation. Fourth, the presence of a control group in all of our studies adds valuable information, as it enables us to draw conclusions concerning the deleterious im- pact of performance-approach goals on performance. Indeed, one important aim of the present studies was to prevent the use of cheating or surface processing that might act as potential facilitators of performance. Once again, the modular arithmetic task turned out to be particularly suitable, as previous research (Beilock $\&$ DeCaro, 2007) has identified the use of shortcut solving strategies that hinder accuracy. In the present research, allowing that each problem appeared only once, and that the experimental setting left no time for participants to prepare for the test, cheating was highly unlikely to occur.

This work contributes to research on motivation, to the extent that it helps to clarify the contradiction between performanceapproach goals' positive impact on achievement and some "disruptive motivational concerns" (Elliot \& Moller, 2003, p. 349) associated with their endorsement; indeed, it highlights the specific situations under which these goals exert a negative influence on performance. To our knowledge, the findings presented in this research constitute the first experimental evidence of the distractive consequences of performance-approach goals. This research thus depicts performance-approach goals as a potential interfering factor for task focus, a finding that revives the debate seemingly closed by Senko et al. (2011, p. 33), who concluded there was a "dearth of evidence for the task distraction hypothesis." Noticeably, the present finding emerged from a stringent laboratory test, in which we have tried to address some shortcomings that we believe could have interfered, in previous research, with the test of this specific hypothesis. Hence, we hope that the analysis that led to this test may encourage achievement goal researchers to reconsider, and test, the sheer effects of performance-approach goals on a wide range of cognitive and behavioral outcomes.

Moreover, our results also represent an important extension of the literature that studies how evaluative pressure impairs performance-and in particular that on the "choking under pressure" effect (Beilock et al., 2004)—by emphasizing how the manipulation of goals that motivate participants to outperform others has the potential to generate distractive outcome concerns simultaneous to task solving, thereby impairing cognitive performance. We believe that these promising results can encourage cross-fertilization between two very active areas of research-namely, achievement goals and evaluative pressure- that so far have developed independently. For example, it could prove interesting to clarify whether anxiety-which is assumed to play a key role in the choking under pressure effect-is partly involved in the decrease in performance consecutive to performance-approach goal manipulation. While high-pressure situations such as those manipulated by Beilock and colleagues put the emphasis on various stressful stakes (monetary incentives, peer pressure, and social evaluation), our performance-approach goal induction put the emphasis merely on the importance of getting a high score and outperforming others, but it still produced an impairment of cognitive performance.

One limitation of the present work is that it does not provide any assessment of performance-avoidance goals, which could arguably be partly responsible for the detrimental consequences of performance-approach goal manipulation. Indeed, it could be suggested that emphasizing the importance of doing better than other participants on a new task led some individuals to focus their efforts on avoiding underachievement (performance-avoidance goals), rather than on reaching the highest score (performance- 
approach goals). Even if such an option cannot be definitely ruled out, it is worth underlining that the performance-approach goal manipulation used in Experiments 2 and 3 (i.e., explicit instructions) had previously been pretested, validated, and found to have separate effects from a performance-avoidance goal manipulation (Darnon et al., 2007, pilot study) and that the efficacy of the priming words (Experiment 1) had been assessed in the present research via a pilot study.

It is also worth pointing out that the present studies, because they were conducted in a laboratory setting, do not allow the conclusions to be extended to more natural settings, that is, a classroom environment. More specifically, precise situations where such a performance decrement might be prone to occur still remain to be studied. For example, pop quizzes might prove stimulating to examine, as students, in this specific situation, have to face the pressure of being evaluated without possibly having had the opportunity to strategically prepare for it. Hence, on the basis of the results reported above, the performance of students who primarily adopt performance-approach goals might suffer from distraction. These speculations allow us to address an important issue, that of the cognitive performance that follows striving for excellence, especially in light of the prominence of selection processes in academic contexts, and given that "in order to succeed in the university system, one has to get better grades than others, which implies the endorsement of performance-approach goals" (Darnon, Dompnier, et al., 2009, p. 129). These dynamics might also be relevant for work and organizational settings, where selection processes may shape the form and effects of achievement goals (e.g., Janssen \& Van Yperen, 2004).

\section{References}

Ames, C. (1992). Classrooms: Goals, structures, and student motivation. Journal of Educational Psychology, 84, 261-271. doi:10.1037/00220663.84.3.261

Ames, C., \& Archer, J. (1988). Achievement goals in the classroom: Students' learning strategies and motivation processes. Journal of Educational Psychology, 80, 260-267. doi:10.1037/0022-0663.80.3.260

Anderman, E., \& Danner, F. (2008). Achievement goals and academic cheating. International Review of Social Psychology, 21, 155-180.

Baddeley, A. D. (1986). Working memory. Oxford, England: Oxford University Press.

Baddeley, A. D. (1996). Exploring the central executive. The Quarterly Journal of Experimental Psychology A: Human Experimental Psychology, 49(A), 5-28.

Baddeley, A. D. (2000). The episodic buffer: A new component of working memory? Trends in Cognitive Sciences, 4, 417-423. doi:10.1016/ S1364-6613(00)01538-2

Baddeley, A. D., \& Hitch, G. (1974). Working memory. In G. H. Bower (Ed.), The psychology of learning and motivation (pp. 47-90). New York, NY: Academic Press.

Barron, K. E., \& Harackiewicz, J. M. (2001). Achievement goals and optimal motivation: Testing multiple goal models. Journal of Personality and Social Psychology, 80, 706-722. doi:10.1037/0022-3514.80.5 .706

Barron, K. E., \& Harackiewicz, J. M. (2003). Revisiting the benefits of performance-approach goals in the college classroom: Exploring the role of goals in advanced college courses. International Journal of Educational Research, 39, 357-374. doi:10.1016/j.ijer.2004.06.004

Baumeister, R. F. (1984). Choking under pressure: Self-consciousness and paradoxical effects of incentives on skillful performance. Journal of
Personality and Social Psychology, 46, 610-620. doi:10.1037/00223514.46.3.610

Beilock, S. L., \& Carr, T. H. (2001). On the fragility of skilled performance: What governs choking under pressure? Journal of Experimental Psychology: General, 130, 701-725. doi:10.1037/0096-3445.130.4.701

Beilock, S. L., \& Carr, T. H. (2005). When high-powered people fail: Working memory and "choking under pressure" in math. Psychological Science, 16, 101-105. doi:10.1111/j.0956-7976.2005.00789.x

Beilock, S. L., \& DeCaro, M. S. (2007). From poor performance to success under stress: Working memory, strategy selection, and mathematical problem solving under pressure. Journal of Experimental Psychology: Learning, Memory, \& Cognition, 33, 983-998. doi:10.1037/0278-7393 .33.6.983

Beilock, S. L., Kulp, C. A., Holt, L. E., \& Carr, T. H. (2004). More on the fragility of performance: Choking under pressure in mathematical problem solving. Journal of Experimental Psychology: General, 133, $584-$ 600. doi:10.1037/0096-3445.133.4.584

Beilock, S. L., Rydell, R. J., \& McConnell, A. R. (2007). Stereotype threat and working memory: Mechanisms, alleviation, and spillover. Journal of Experimental Psychology: General, 136, 256-276. doi:10.1037/00963445.136.2.256

Butler, R. (1992). What young people want to know when: Effects of mastery and ability goals on interest in different kinds of social comparisons. Journal of Personality and Social Psychology, 62, 934-943. doi:10.1037/0022-3514.62.6.934

Conroy, D. E., \& Elliot, A. J. (2004). Fear of failure and achievement goals in sport: Addressing the issue of the chicken and the egg. Anxiety, Stress \& Coping: An International Journal, 17, 271-285.

Cowan, N. (2001). The magical number 4 in short-term memory: A reconsideration of mental storage capacity. Behavioral and Brain Sciences, 24, 87-185. doi:10.1017/S0140525X01003922

Cury, F., Elliot, A. J., Da Fonseca, D., \& Moller, A. C. (2006). The social-cognitive model of achievement motivation and the $2 \times 2$ achievement goal framework. Journal of Personality and Social Psychology, 90, 666-679. doi:10.1037/0022-3514.90.4.666

Darnon, C., Butera, F., Mugny, G., Quiamzade, A., \& Hulleman, C. S. (2009). "Too complex for me!" Why do performance-approach and performance-avoidance goals predict exam performance? European Journal of Psychology of Education, 24, 423-434. doi:10.1007/ BF03178759

Darnon, C., Dompnier, B., Delmas, F., Pulfrey, C., \& Butera, F. (2009). Achievement goal promotion at university: Social desirability and social utility of mastery and performance goals. Journal of Personality and Social Psychology, 96, 119-134. doi:10.1037/a0012824

Darnon, C., Harackiewicz, J., Butera, F., Mugny, G., \& Quiamzade, A. (2007). Performance-approach and performance-avoidance goals: When uncertainty makes a difference. Personality and Social Psychology Bulletin, 33, 813-827. doi:10.1177/0146167207301022

Darnon, C., Muller, D., Schrager, S. M., Pannuzzo, N., \& Butera, F. (2006). Mastery and performance goals predict epistemic and relational conflict regulation. Journal of Educational Psychology, 98, 766-776. doi:10.1037/0022-0663.98.4.766

DeCaro, M. S., Rotar, K. E., Kendra, M. S., \& Beilock, S. L. (2010) Diagnosing and alleviating the impact of performance pressure on mathematical problem solving. The Quarterly Journal of Experimental Psychology, 63, 1619-1630. doi:10.1080/17470210903474286

DeStefano, D., \& LeFevre, J.-A. (2004). The role of working memory in mental arithmetic. European Journal of Cognitive Psychology, 16, 353 386. doi: $10.1080 / 09541440244000328$

Dompnier, B., Darnon, C., \& Butera, F. (2009). Faking the desire to learn: A clarification of the link between mastery goals and academic achievement. Psychological Science, 20, 939-943. doi:10.1111/j.1467-9280 .2009.02384.x 
Dweck, C. S. (1986). Motivational processes affect learning. American Psychologist, 41, 1040-1048. doi:10.1037/0003-066X.41.10.1040

Dweck, C. S., \& Leggett, E. L. (1988). A social-cognitive approach to motivation and personality. Psychological Review, 95, 256-273. doi: 10.1037/0033-295X.95.2.256

Elliot, A. J. (1997). Integrating the "classic" and "contemporary" approaches to achievement motivation: A hierarchical model of approach and avoidance motivation. In M. Maehr \& P. Pintrich (Eds.), Advances in motivation and achievement (Vol. 10, pp. 143-179). Greenwich, CT: JAI Press.

Elliot, A. J. (1999). Approach and avoidance motivation and achievement goals. Educational Psychologist, 34, 169-189. doi:10.1207/ s15326985ep3403_3

Elliot, A. J., \& Church, M. A. (1997). A hierarchical model of approach and avoidance achievement motivation. Journal of Personality and Social Psychology, 72, 218-232. doi:10.1037/0022-3514.72.1.218

Elliot, A. J., \& Harackiewicz, J. M. (1996). Approach and avoidance achievement goals and intrinsic motivation: A mediational analysis. Journal of Personality and Social Psychology, 70, 461-475. doi: 10.1037/0022-3514.70.3.461

Elliot, A. J., \& McGregor, H. A. (1999). Test anxiety and the hierarchical model of approach and avoidance achievement motivation. Journal of Personality and Social Psychology, 76, 628-644. doi:10.1037/00223514.76.4.628

Elliot, A. J., \& McGregor, H. A. (2001). A $2 \times 2$ achievement goal framework. Journal of Personality and Social Psychology, 80, 501-519. doi:10.1037/0022-3514.80.3.501

Elliot, A. J., McGregor, H. A., \& Gable, S. (1999). Achievement goals, study strategies, and exam performance: A mediational analysis. Journal of Educational Psychology, 91, 549-563. doi:10.1037/0022-0663.91.3 .549

Elliot, A. J., \& Moller, A. C. (2003). Performance-approach goals: Good or bad forms of regulation? International Journal of Educational Research, 39, 339-356. doi:10.1016/j.ijer.2004.06.003

Elliot, A. J., \& Murayama, K. (2008). On the measurement of achievement goals: Critique, illustration, and application. Journal of Educational Psychology, 100, 613-628. doi:10.1037/0022-0663.100.3.613

Elliot, A. J., \& Sheldon, K. M. (1997). Avoidance achievement motivation: A personal goals analysis. Journal of Personality and Social Psychology, 73, 171-185. doi:10.1037/0022-3514.73.1.171

Elliot, A. J., Shell, M. V., Henry, K. B., \& Maier, M. A. (2005). Achievement goals, performance contingencies, and performance attainment: An experimental test. Journal of Educational Psychology, 97, 630-640. doi:10.1037/0022-0663.97.4.630

Engle, R. W. (2001). What is working-memory capacity? In H. L. Roediger, III \& J. S. Nairne (Eds.), The nature of remembering: Essays in Honor of Robert G. Crowder (pp. 297-314). Washington, DC: American Psychological Association. doi:10.1037/10394-016

Engle, R. W. (2002). Working memory capacity as executive attention. Current Directions in Psychological Science, 11, 19-23. doi:10.1111/ $1467-8721.00160$

Gimmig, D., Huguet, P., Caverni, J.-P., \& Cury, F. (2006). Choking under pressure and working-memory capacity: When performance pressure reduces fluid intelligence. Psychonomic Bulletin \& Review, 13, 10051010. doi:10.3758/BF03213916

Grant, H., \& Dweck, C. S. (2003). Clarifying achievement goals and their impact. Journal of Personality and Social Psychology, 85, 541-553. doi:10.1037/0022-3514.85.3.541

Harackiewicz, J. M., Barron, K. E., Carter, S. M., Lehto, A. T., \& Elliot, A. J. (1997). Predictors and consequences of achievement goals in the college classroom: Maintaining interest and making the grade. Journal of Personality and Social Psychology, 73, 1284-1295. doi:10.1037/ 0022-3514.73.6.1284
Harackiewicz, J. M., Barron, K. E., Tauer, J. M., Carter, S. M., \& Elliot, A. J. (2000). Short-term and long-term consequences of achievement goals: Predicting interest and performance over time. Journal of Educational Psychology, 92, 316-330. doi:10.1037/0022-0663.92.2.316

Harackiewicz, J. M., Barron, K. E., Tauer, J. M., \& Elliot, A. J. (2002) Predicting success in college: A longitudinal study of achievement goals and ability measures as predictors of interest and performance from freshman year through graduation. Journal of Educational Psychology, 94, 562-575. doi:10.1037/0022-0663.94.3.562

Harackiewicz, J. M., Manderlink, G., \& Sansone, C. (1984). Rewarding pinball wizardry: Effects of evaluation and cue value on intrinsic interest. Journal of Personality and Social Psychology, 47, 287-300. doi: 10.1037/0022-3514.47.2.287

Jagacinski, C. M., \& Nicholls, J. G. (1987). Competence and affect in task involvement and ego involvement: The impact of social comparison information. Journal of Educational Psychology, 79, 107-114. doi: 10.1037/0022-0663.79.2.107

Janssen, O., \& Van Yperen, N. W. (2004). Employees' goal orientations, the quality of leader-member exchange, and the outcomes of job performance and job satisfaction. Academy of Management Journal, 47, 368-384. doi:10.2307/20159587

Judd, C. M., \& McClelland, G. H. (1989). Data analysis: A model comparison approach. San Diego, CA: Harcourt Brace Jovanovich.

Koole, S. L., Smeets, K., van Knippenberg, A., \& Dijksterhuis, A. (1999). The cessation of rumination through self-affirmation. Journal of Personality and Social Psychology, 77, 111-125. doi:10.1037/0022-3514 .77.1.111

Linnenbrink, E. A., Ryan, A. M., \& Pintrich, P. R. (1999). The role of goals and affect in working memory functioning. Learning and Individual Differences, 11, 213-230. doi:10.1016/S1041-6080(00)80006-0

Mangels, J. A., Butterfield, B., Lamb, J., Good, C. D., \& Dweck, C. S (2006). Why do beliefs about intelligence influence learning success? A social cognitive neuroscience model. Social Cognitive and Affective Neuroscience, 1, 75-86. doi:10.1093/scan/ns1013

Meece, J. L., Blumenfeld, P. C., \& Hoyle, R. H. (1988). Students' goal orientations and cognitive engagement in classroom activities. Journal of Educational Psychology, 80, 514-523. doi:10.1037/0022-0663.80.4 .514

Miyake, A., \& Shah, P. (Eds.). (1999). Models of working memory: Mechanisms of active maintenance and executive control. New York, NY: Cambridge University Press. doi:10.1017/CBO9781139174909

Muller, D., \& Butera, F. (2007). The focusing effect of self-evaluation threat in coaction and social comparison. Journal of Personality and Social Psychology, 93, 194-211. doi:10.1037/0022-3514.93.2.194

Murdock, T. B., \& Anderman, E. M. (2006). Motivational perspectives on student cheating: Toward an integrated model of academic dishonesty. Educational Psychologist, 41, 129-145. doi:10.1207/ s15326985ep4103_1

Navon, D. (1984). Resources-A theoretical soup stone? Psychological Review, 91, 216-234. doi:10.1037/0033-295X.91.2.216

Nicholls, J. G. (1984). Achievement motivation: Conceptions of ability, subjective experience, task choice, and performance. Psychological Review, 91, 328-346. doi:10.1037/0033-295X.91.3.328

Norman, D. A., \& Bobrow, D. G. (1975). On data-limited and resourcelimited processes. Cognitive Psychology, 7, 44-64. doi:10.1016/00100285(75)90004-3

Pekrun, R., Elliot, A. J., \& Maier, M. A. (2009). Achievement goals and achievement emotions: Testing a model of their joint relations with academic performance. Journal of Educational Psychology, 101, 115135. doi:10.1037/a0013383

Poortvliet, P. M., Janssen, O., Van Yperen, N. W., \& Van de Vliert, E. (2007). Achievement goals and interpersonal behavior: How mastery and performance goals shape information exchange. Personality and Social Psychology Bulletin, 33, 1435-1447. 
Pryor, J. H., Hurtado, S., DeAngelo, L., Palucki Blake, L., \& Tran, S. (2010). The American freshman: National norms Fall 2010. Los Angeles, CA: Higher Education Research Institute, University of California, Los Angeles.

Ryan, A. M., \& Pintrich, P. R. (1997). Should I ask for help? The role of motivation and attitudes in adolescents' help seeking in math class. Journal of Educational Psychology, 89, 329-341. doi:10.1037/00220663.89.2.329

Sage, L., \& Kavussanu, M. (2007). The effects of goal involvement on moral behavior in an experimentally manipulated competitive setting. Journal of Sport \& Exercise Psychology, 29, 190-207.

Sansone, C. (1986). A question of competence: The effects of competence and task feedback on intrinsic interest. Journal of Personality and Social Psychology, 51, 918-931. doi:10.1037/0022-3514.51.5.918

Sarason, I. G. (1984). Stress, anxiety, and cognitive interference: Reactions to tests. Journal of Personality and Social Psychology, 46, 929-938. doi:10.1037/0022-3514.46.4.929

Schmader, T., \& Johns, M. (2003). Converging evidence that stereotype threat reduces working memory capacity. Journal of Personality and Social Psychology, 85, 440-452. doi:10.1037/0022-3514.85.3.440

Seibert, P. S., \& Ellis, H. C. (1991). Irrelevant thoughts, emotional mood states, and cognitive task performance. Memory \& Cognition, 19, 507513. doi:10.3758/BF03199574

Senko, C., \& Harackiewicz, J. M. (2002). Performance goals: The moderating role of context, achievement orientation, and feedback. Journal of Experimental Social Psychology, 38, 603-610. doi:10.1016/S00221031(02)00503-6

Senko, C., \& Harackiewicz, J. M. (2005). Achievement goals, task performance, and interest: Why perceived goal difficulty matters. Personality and Social Psychology Bulletin, 31, 1739-1753. doi:10.1177/ 0146167205281128

Senko, C., Hulleman, C. S., \& Harackiewicz, J. M. (2011). Achievement goal theory at the crossroads: Old controversies, current challenges, and new directions. Educational Psychologist, 46, 26-47. doi:10.1080/ 00461520.2011 .538646
Sideridis, G. D. (2005). Goal orientation, academic achievement, and depression: Evidence in favor of a revised goal theory framework. Journal of Educational Psychology, 97, 366-375. doi:10.1037/00220663.97.3.366

Trbovich, P. L., \& LeFevre, J.-A. (2003). Phonological and visual working memory in mental addition. Memory \& Cognition, 31, 738-745. doi: 10.3758/BF03196112

Van Yperen, N. W. (2003). Task interest and actual performance: The moderating effects of assigned and adopted purpose goals. Journal of Personality and Social Psychology, 85, 1006-1015. doi:10.1037/00223514.85.6.1006

Van Yperen, N. W., Hamstra, M. R. W., \& Van der Klauw, M. (2011). To win, or not to lose, at any cost: The impact of achievement goals on cheating. British Journal of Management, 22, S5-S15. doi:10.1111/j .1467-8551.2010.00702.x

Wegner, D. M. (1994). Ironic processes of mental control. Psychological Review, 101, 34-52. doi:10.1037/0033-295X.101.1.34

Wegner, D. M. (2009, July 3). How to think, say, or do precisely the worst thing for any occasion. Science, 325, 48-50. doi:10.1126/science .1167346

Wenzlaff, R. M., \& Wegner, R. M. (2000). Thought suppression. Annual Review of Psychology, 51, 59-91. doi:10.1146/annurev.psych.51.1.59

Wolters, C. A. (2004). Advancing achievement goal theory: Using goal structures and goal orientations to predict students' motivation, cognition, and achievement. Journal of Educational Psychology, 96, 236250. doi:10.1037/0022-0663.96.2.236

Yzerbyt, V., Muller, D., \& Judd, C. M. (2004). Adjusting researchers' approach to adjustment: On the use of covariates when testing interactions. Journal of Experimental Social Psychology, 40, 424-431. doi: 10.1016/j.jesp.2003.10.001

Received March 7, 2012

Revision received July 7, 2012

Accepted July 9, 2012 